\title{
Evaluation of Seismic Performance of Floating Column Building
}

\author{
Kishalay Maitra*, N. H. M. Kamrujjaman Serker \\ Department of Civil Engineering, Rajshahi University of Engineering \& Technology, Rajshahi, Bangladesh \\ Email address: \\ kishalaymaitra@gmail.com (K. Maitra),kserker@yahoo.com(N.H. M. K. Serker) \\ ${ }^{*}$ Corresponding author
}

To cite this article:

Kishalay Maitra, N. H. M. Kamrujjaman Serker. Evaluation of Seismic Performance of Floating Column Building. American Journal of Civil Engineering. Vol. 6, No. 2, 2018, pp. 55-59. doi: 10.11648/j.ajce.20180602.11

Received: February 15, 2018; Accepted: March 9, 2018; Published: April 2, 2018

\begin{abstract}
In the modern multi-story construction, floating column is an unavoidable feature of buildings. Such features are highly undesirable in building built in seismic prone areas. This study highlights the performance of floating column building and compared with normal building under seismic load. In this study, static and dynamic analyses using response spectrum method have been carried out for multi-story building with and without floating columns. Different cases of the building have been studied by varying the location of floating column and increasing the column size. The results showed that story displacement increased by $56.96 \%$ in floating column building compared to normal building. Torsional irregularity was found when floating column was introduced unsymmetrically. It was also found that fundamental time period was increasing in floating column building and lateral stiffness was decreasing in floating column building. When the lost cross sectional area due to floating columns were distributed among ground floor columns then it was found that story displacement as well as fundamental time period decreased and lateral stiffness increased.
\end{abstract}

Keywords: Floating Column, Seismic Analysis, Static Analysis, Dynamic Analysis, Irregular Building

\section{Introduction}

At present for better parking facilities, open first story is a common feature in commercial and residential building. During earthquake, the behaviour of building depends on its geometrical shape, size and how the earthquake force carried to the ground. Usually in every building load is transferred from horizontal members (beams and slabs) to vertical members (walls and columns) and then to the foundation.

A structure having floating column can be classified as vertically irregular as it causes irregular distribution of mass, strength and stiffness along the building height [11]. Absence of any column at any level of structure changes the load transfer path and load of this floating column is transferred through the horizontal beams below it, known as transfer girders [10].

Previous research showed the building which have floating column at ground floor have most adverse effect of earthquake. This paper explains the behaviour of multi-story floating column building and comparison between floating as well as without floating column structure and values of various parameters like story drift, story displacement etc. on the basis of seismic load.

\subsection{Floating Column}

A column is a vertical compressive member. It transfers superstructure load to the foundation then to the ground. The floating column also a vertical member but its lower end is not connected to the foundation. Its lower end rest on beam which is a horizontal member, this beam transfer the load of floating column to other columns below it. 


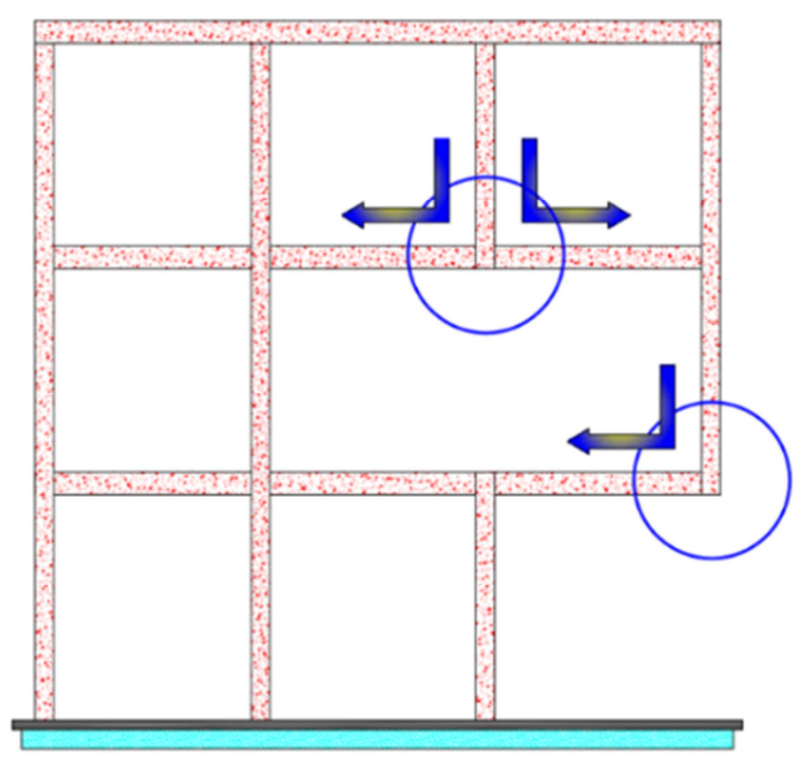

Figure 1. Floating column.

\subsection{Objectives}

The main objectives of this study is to evaluate the performance of floating column building. Followings are the specific objectives of this study.

i. To study the behaviour of multi-story floating column building under earthquake load.

ii. To compare the performance of the floating column building with usual building.

\section{Methodology}

A 10 story arbitrary building with plan area 13440 sq. $\mathrm{ft}$. is considered for study. Bay span in x-direction $16^{\prime}$ and bay span in y-direction 14'. Dimension of beams and columns as well as other properties of the building is specified in table 1 .

Table 1. Geometrical dimensions of the building and material properties.

\begin{tabular}{lll}
\hline Member properties & & \\
\hline Slab & Thickness & $6 "$ \\
& Normal building & $18 " \times 12 "$ \\
Beams & Floating column building & $18 " \times 12 "$ \\
& Exterior & $12 " \times 12 "$ \\
Column & Interior & $15 " \times 12 "$ \\
Concrete & Grade of concrete & $3 \mathrm{ksi}$ \\
Steel & Grade of steel & $60 \mathrm{ksi}$ \\
\hline
\end{tabular}

\subsection{Case 1}

In this case usual building is considered as specified in above. Beams size is considered 18" $\mathrm{x} 12$ " for both $\mathrm{X}$ and $\mathrm{Y}$ direction. Column size considered for exterior 12 " $\mathrm{x} 12$ " and for interior 15 " x 12 ".

\subsection{Case 2}

Here left side edge column of ground floor of the building is sorted out. Other columns properties and their location are same.

\subsection{Case 3}

In this case ground floor column size is increased. Left side column size is sorted out. Exterior column size is considered 14" x 12". And interior column is considered as $16 " x 12 "$.

\subsection{Case 4}

Here all edge side column of ground floor is sorted out. The location and properties of other column and beam are kept same.

\subsection{Case 5}

In this case all edge side column of ground floor is sorted out and ground floor column size is increased. Column size considered as $20 " \times 15$ ".

\section{Methods of Analysis}

Seismic analysis is a major tool in earthquake engineering. It is usually used to determine the response of buildings in a simple manner due to earthquake forces. It is a part of structural analysis and a part of structural design where earthquake is common phenomenon.

The seismic study methods used in the study are-

i. Equivalent Static Analysis

ii. Response Spectrum Analysis

iii. Modal Analysis

\section{Results and Discussions}

\subsection{Story Displacement}

Maximum story displacement profile for all cases obtained from equivalent static method. Load combination used for the analysis is $1.2 \mathrm{DL}+1.0 \mathrm{LL}+1.0$ (Eqy-e).

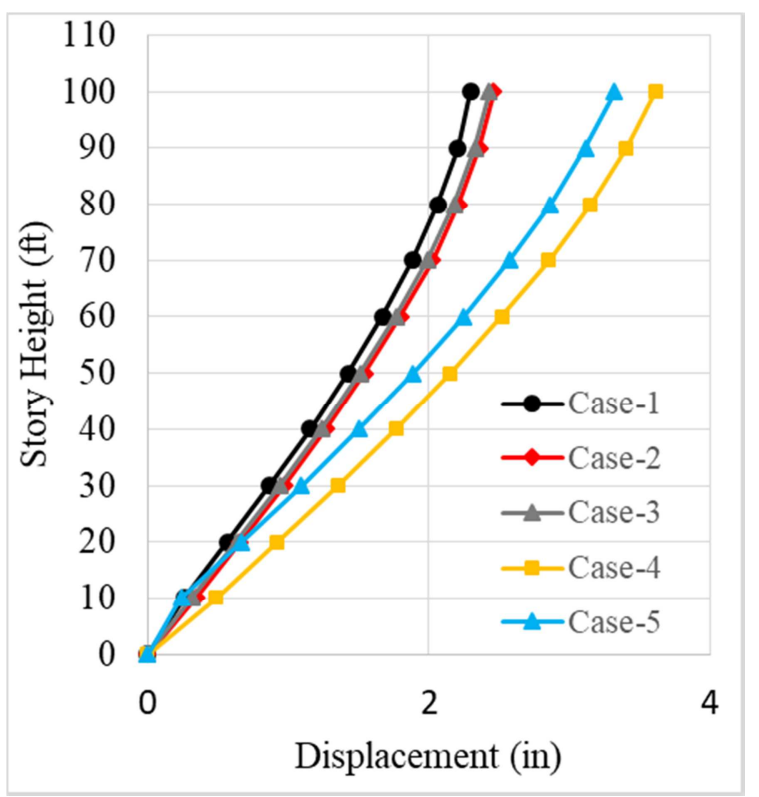

Figure 2. Variation of story displacement with respect to story height. 
Here introducing floating column increase story displacement. In case-2 floating column is introduced in left side edge and in case- 4 floating column is introduced in all edge side, displacement increase respectively $6.96 \%$ and $56.96 \%$. In case-3 and case-5 column size increased on ground floor, displacement decreases for those cases respectively $1.6 \%$ and $8.03 \%$ compared with Case 2 and Case 4.

\subsection{Story Drift}

Story drift profile for all cases obtained from Response Spectrum Analysis (RSA). Response spectrum function graph used as specified in BNBC 2015.

Here in case 1 which is analyzed considering without floating column, maximum story drift at 2 nd story, but in case 2 and case 4 where floating column is introduced, maximum story drift found at 1 st story. Maximum Story drift increased in case 2 and case 4 respectively $15.96 \%$ and $22.57 \%$. In case 3 as well as case 5 maximum story drift decreases for increasing column size and maximum story drift observed at $2^{\text {nd }}$ story.

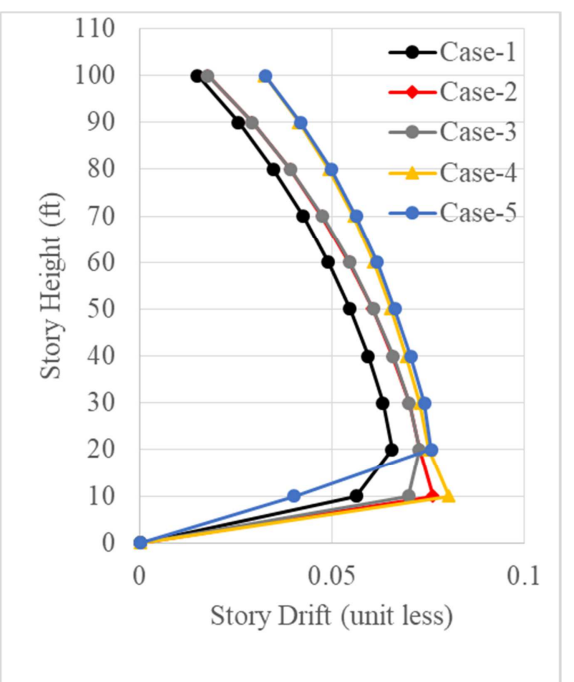

Figure 3. Variation of story drift with respect to story height.

\subsection{Torsional Irregularity Check}

According to BNBC code 2015 , if $D_{\max } / D_{\text {avg }}$ is greater than 1.2 torsional irregularity exist in the building and if $\mathrm{D}_{\max }$ $/ \mathrm{D}_{\mathrm{avg}}$ is greater than 1.4 extreme torsional irregularity exist. In this study $1.2 \mathrm{DL}+1.0 \mathrm{LL}+1.0$ (Eqy-e) is considered for checking torsional irregularity.

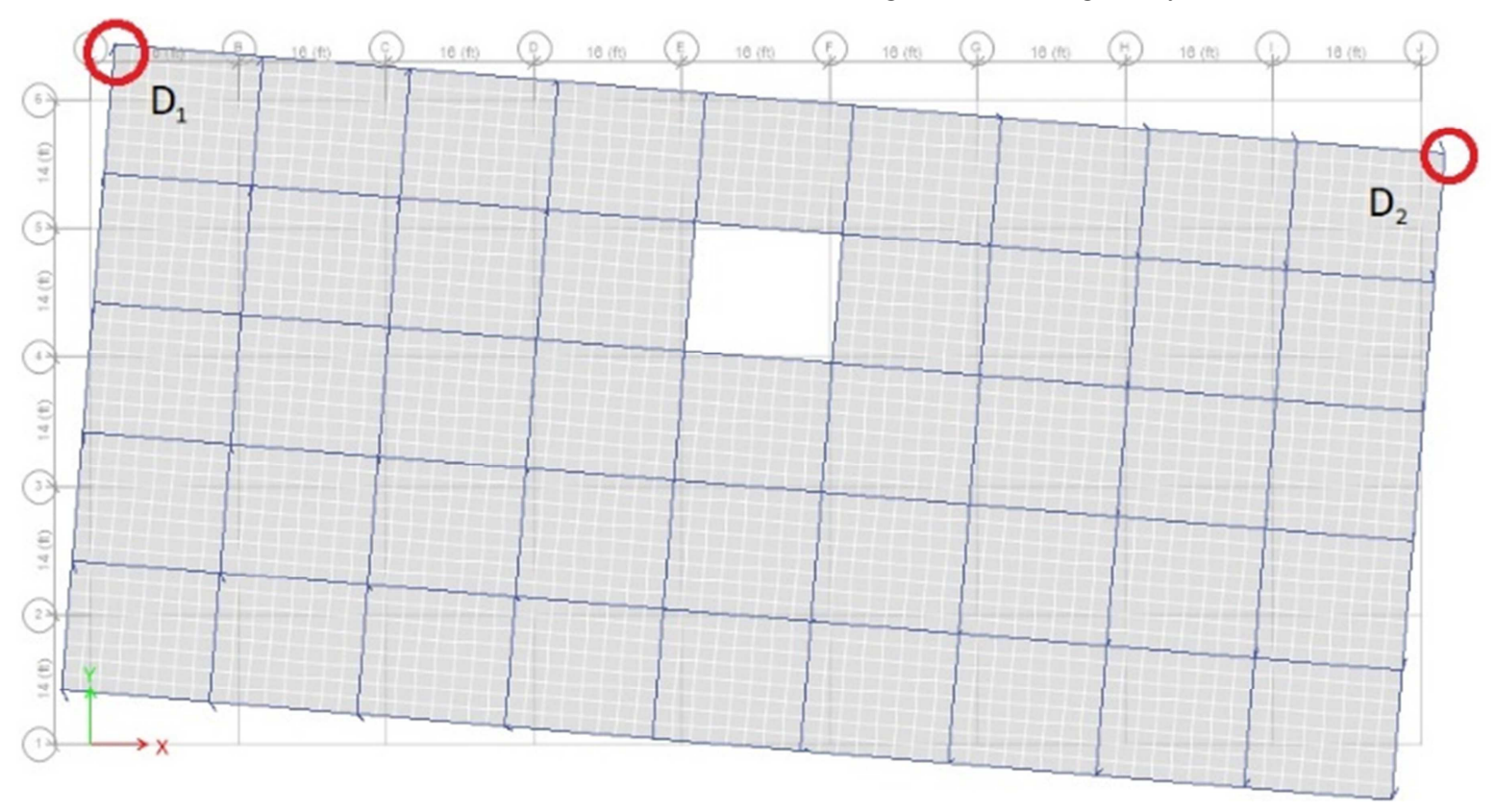

Figure 4. Deformed shape of top story.

Here,

$\mathrm{D}_{1}$ and $\mathrm{D}_{2}$ are displacement of corner point of top floor.

$\mathrm{D}_{\max }=$ maximum displacement between

$\mathrm{D}_{1}$ and $\mathrm{D}_{2}$

$\mathrm{D}_{\mathrm{avg}}=$ Average of $\mathrm{D}_{1}$ and $\mathrm{D}_{2}$

Case 1:

$\frac{\mathrm{D}_{\max }}{\mathrm{D}_{\mathrm{avg}}}=\frac{2.29}{\frac{2.29+1.55}{2}}=1.19<1.2$, Torsional irregularity does not exist.

Case 2:
$\frac{D_{\max }}{D_{\text {avg }}}=\frac{2.46}{\frac{2.46+1.52}{2}}=1.24<1.2$, Torsional irregularity exist.

Case 3:

$\frac{\mathrm{D}_{\max }}{\mathrm{D}_{\text {avg }}}=\frac{2.42}{\frac{2.42+1.51}{2}}=1.23<1.2$, Torsional irregularity exist.

Case 4:

$\frac{D_{\max }}{D_{\text {avg }}}=\frac{3.6}{\frac{3.6+2.59}{2}}=1.16<1.2$, Torsional irregularity does not exist.

Case 5: 
$\frac{\mathrm{D}_{\max }}{\mathrm{D}_{\mathrm{avg}}}=\frac{3.32}{\frac{3.32+2.41}{2}}=1.158<1.2$, Torsional irregularity does not exist.

In this study it was observed that when floating column is introduced unsymmetrically then torsional irregularity exist. In Case 2 and Case 3 floating is only at left side, so those case exhibit torsional irregularity. On the other hand in Case 4 and Case 5 floating column is introduced symmetrically. This case don't show torsional irregularity. Here also observed that column size or maximum story displacement is not the main fact on torsional irregularity. Here in Case 4 maximum story displacement 3.6 inch which is greater than the maximum story displacement of Case 2. So position of the floating column is main determining fact of torsional irregularity.

\subsection{Story Stiffness}

In this study story stiffness observed from static analysis and load case Eqy is considered for determining story stiffness.

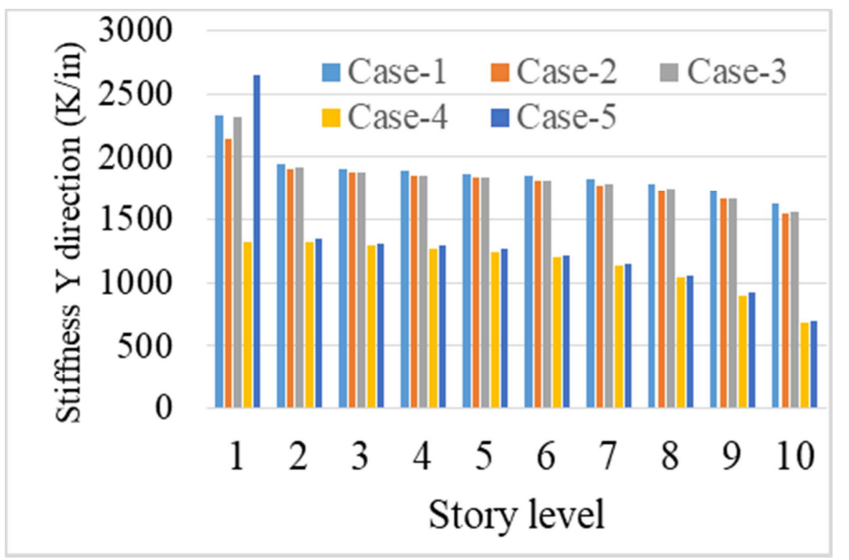

Figure 5. Variation of story stiffness of various cases.

According to BNBC code 2015, A soft story is one in which the lateral stiffness is less than $70 \%$ of that in the story above or less than $80 \%$ of the average lateral stiffness of the three story above irregularity. An extreme soft story is defined where its lateral stiffness is less than $60 \%$ of that in the story above or less than $70 \%$ of the average lateral stiffness of the three story above irregularity. In this study, there is no soft story cases but lateral stiffness decreases for introducing floating column as well as lateral stiffness increases due to increase of column size.

\subsection{Fundamental Time Period}

Fundamental time period is the time taken by the building to undergo a cycle of to and fro movement. In this study fundamental time period determined from modal analysis.

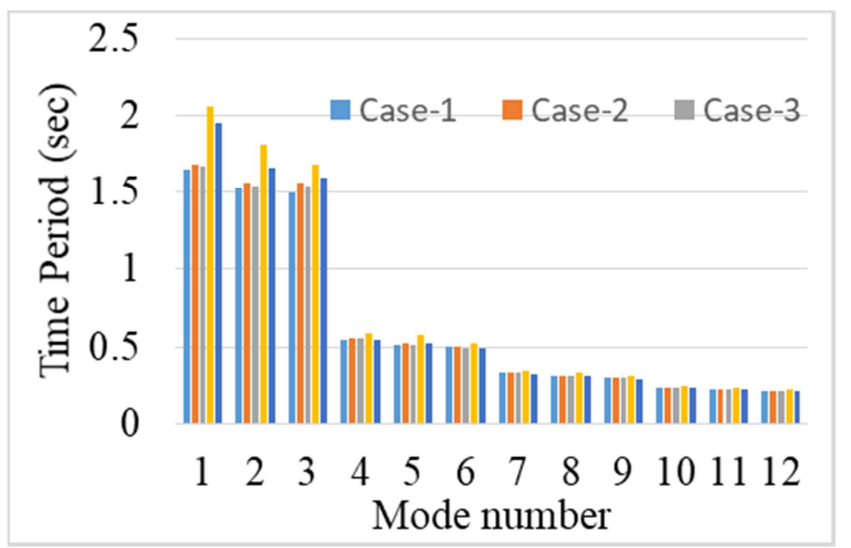

Figure 6. Variation of fundamental time period of various cases.

It is observed that fundamental time period is increasing due to introduction of floating column. As fundamental time period increase, it decreases the overall stiffness of the building. On the other hand fundamental time period decrease some extent due to increase ground floor column.

\subsection{Modal Frequencies}

Mode frequencies is observed using modal analysis by Eigen.

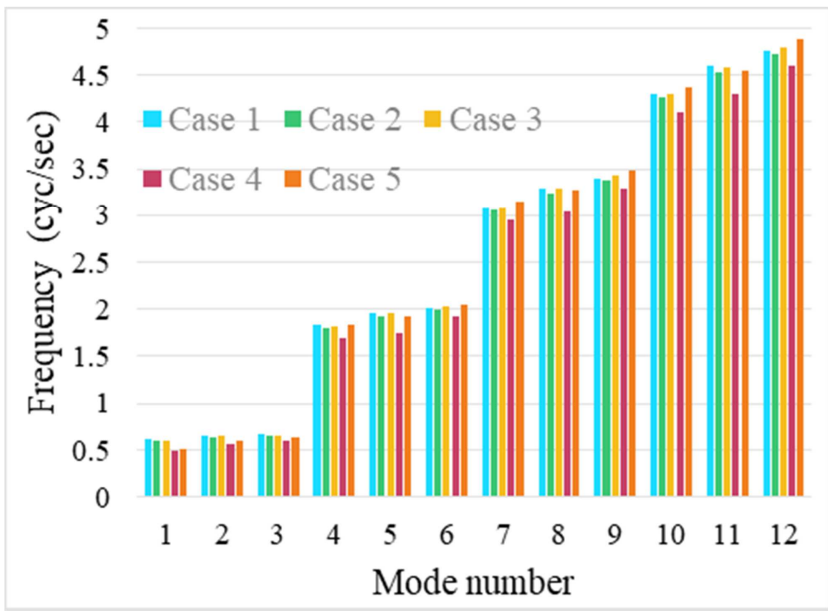

Figure 7. Variation of frequency of various cases.

From the modal frequency, it is found that frequency is lower for each mode in floating column building. So that floating column building tends to more flexible than usual. In Case 3 and Case 5 frequency is higher because ground floor column size is increased and building become stiffer.

\section{Conclusions and Recommendations}

In this study, the behaviour of the buildings with and without floating columns are analyzed under seismic load. Analysis is carried out on a building by comparing five cases. Following are some of the conclusions which are drawn on the basis of the study.

i. Maximum story displacement and story drift is more in floating column building compared to normal building. 
ii. Torsional irregularity exist in floating column building in Case 2 and Case 3 where floating column is introduced only left side column but in Case 4 and Case 5 where all edge side is removed but torsional irregularity does not exist. So, it can be concluded that torsional irregularity does not depend on floating column number or ground floor column size, its mainly depend on floating column location.

iii. Story stiffness is less in floating column building compared to normal building but when ground floor column size increases then story stiffness increase in floating column building.

iv. Fundamental time period of floating column building is greater than normal building.

v. From mode shape it is observed that when floating column is provided unsymmetrically then torsional mode is found early compared to normal and symmetrical floating column building.

Hence, from the study it can be concluded that as far as possible, the floating columns are to be avoided especially in the seismic prone areas and if not possible then floating column should be provided symmetrically to avoid torsional irregularity as well as column size should be increased to get rid of from soft story effect.

\section{References}

[1] Awkar J. C. and Lui E. M. (1997), "Seismic Analysis and Response of Multistory Semi-Rigid Frames", Journal of Engineering Structures, Volume 21, Issue 5, Page no: 425442 .

[2] Brodericka B. M., Elghazouli A. Y. and Goggins J. (2008), "Earthquake Testing and Response Analysis of Concentrically-Braced and Sub-Frames", Journal of constructional Steel Research, volume 64, Issue 9, Page no: 997-1007.
[3] BANGLADESH NATIONAL BUILDING CODE (Final Draft, 2015)

[4] Kavya N., Manjunatha k. and Dyavappanavar S. P. (2015), "Seismic Evaluation of Multistory RC Building With and Without Floating Columns", IEEE Trans. Power System, vol. 19, no. 1, pp. 356-365.

[5] Malaviya P. and Saurav K. (2014), "Comparative Study of Effect of Floating Columns on The Cost Analysis of A Structure Designed on Staad Pro V8i”, IEEE Trans. Power System, vol. 19, no. 1, pp. 356-365.

[6] Maison B. F. and Ventura C. E. (1991), "Dynamic Analysis of Thirteen Story Building", Journal of Structural Engineering, Vol. 117, No. 12, Page no: 3783-3803.

[7] Nanabala S. G., Ramancharla P. K. and Arunakanthi E. (2014), "Seismic Analysis of A Normal Building and Floating Column Building", International Journal of Engineering Research \& Technology (IJERT), Vol. 3 Issue 9.

[8] Nautiyal P., Akhtar S. and Batham G. (2014), "Seismic Response Evaluation of RC Frame Building With Floating Column Considering Different Soil Conditions", IEEE Trans. Power System, vol. 19, no. 1, pp. 356-365.

[9] Singla S. and Rahman E. A. (2015), "Effect of Floating Columns on Seismic Response of Multi-Storeyed RC Framed Building", International Journal of Engineering Research \& Technology, vol. 4 Issue 06.

[10] Srikanth. M. K, Yogeendra. R. H. (2014), "Seismic Response of Complex Buildings With Floating Column For Zone II And Zone V", International journal of Engineering ResearchOnline, vol. 02, pp. 01-11.

[11] Susnato B. and Patro S. K. (2014), "Estimation of The ParkAng Damage Index For Floating Column Building With Infill Wall”, International Journal of Civil, Architectural, Structural and Construction Engineering, Vol. 08, pp. 760-763. 